\title{
RUANG KERJA BERSAMA DENGAN REPARASI OTOMOTIF
}

\author{
Aditya Jovianto $^{1)}$, Stephanus Huwae ${ }^{2)}$ \\ 1)Program Studi S1 Arsitektur, Fakultas Teknik, Universitas Tarumanagara, adityajovianto@yahoo.com \\ 2) Program Studi S1 Arsitektur, Fakultas Teknik, Universitas Tarumanagara, ituuuuut@yahoo.com
}

\begin{abstract}
Abstrak
Usia kerja sekarang ini kebanyakan adalah generasi milenial yang menyukai tempat kerja dengan kriteria yang tidak terkesan sebagai tempat tertutup/terkurung. Tempat kerja yang dapat memungkinkan mereka untuk bisa produktif namun tetap bisa berkomunikasi dengan orang lain, membangun relasi dengan orang lain dan berkolaborasi antara satu sama lain. Generasi milenial lebih menyukai untuk bekerja di tempat-tempat seperti cafe atau restoran cepat saji. Namun sebenarnya tempat tersebut tidak cocok menjadi tempat untuk bekerja karena banyak orang dengan kepentingan berbeda berkumpul disana seperti berbincang dengan teman, makan/minum, bekerja, atau bahkan menyaksikan sebuah tontonan yang sedang hangat. Jenis proyek yang diputuskan untuk didesain adalah bangunan dengan fungsi kantor dengan ruang kerja bersama (Co-Working Space) untuk memenuhi kebutuhan generasi milenial serta mengembangkan dan mempopulerkan jenis tempat kerja Co-Working Space terutama di Jakarta. Setelah dilakukan penelitian dan pencarian data, didapati bahwa daerah Jakarta Utara memiliki paling sedikit Co-Working Space. Kemudian dipilihlah daerah kelurahan Sungai Bambu, kecamatan Tanjung Priok dengan luas tapak sebesar $7450 \mathrm{~m}^{2}$. Metode yang digunakan adalah menggunakan metode pola, dimana program melihat pola bangunan lingkungan sekitar dekat dengan kawasan perkantoran otomotif yang masing - masing kebanyakan memilki gudang sendiri. Oleh karena itu program dalam proyek ini meliputi ruang kerja bersama, kantor sewa, bengkel, gudang, dan program tambahan food court. Pola juga digunakan untuk mendapatkan bentuk gubahan massa, dimana area kanan dan kiri tapak merupakan bangunan yang memilki bentuk grid yang memanjang yaitu gudang dan ruko.
\end{abstract}

Kata kunci: generasi milenial; kolaborasi; ruang kerja bersama

\begin{abstract}
Today's working age is mostly millennial generations who like workplaces that are not impressed as a closed / confined place. Workplaces that can enable them to be productive but still be able to communicate with others, build relationships with others and collaborate with each other. Therefore now they prefer to work in places like fast food cafes or restaurants. But actually the places is not suitable to be a place to work because many people with different interests gather there such as chatting with friends, eating / drinking, working, or even watching a spectacle that is hot. The type of project decided to be designed is a building with office functions with a Co-Working Space to meet the needs of the millennial generation, develop and popularize the type of workplace Co-Working Space especially in Jakarta. After conducting research and data searching, it was found that the North Jakarta area had the least number of Co-Working Space. Then the Sungai Bambu urban village was chosen, with Tanjung Priok sub-district with a site size of $7450 \mathrm{~m} 2$. The method used is using the pattern method, where the program looks at the pattern of the surrounding neighborhood building near the automotive office area, each of which has its own warehouse. Therefore the program in this project includes joint workspaces, rental offices, workshops, warehouses, and additional program foodcourt. The pattern is also used to get a form of mass composition, where the right and left areas of the site are buildings that have elongated grid shapes, namely warehouse and shop.
\end{abstract}

Keywords: co-Working space; collaboration; millennial's 


\section{PENDAHULUAN}

\section{Latar Belakang}

Menyewa kantor di Jakarta pasti akan mengeluarkan biaya yang mahal, untuk bisnis yang sudah besar dan berkembang mungkin tidak masalah, tetapi bagi para pemilik bisnis baru atau start up dan bahkan para freelancers, menyewa kantor sendiri itu berat. Untuk menyimpan uang, generasi milenial lebih memilih untuk bekerja di rumah, coffee shop atau cafe terdekat. Tetapi bekerja di rumah, walau tidak mengeluarkan biaya, merupakan suatu tantangan sendiri, karena susah untuk membangun disiplin kerja di tempat istirahat. Selain itu, bekerja di cafe atau coffee shop mewajibkan pendatangnya untuk membeli kopi, makanan atau minuman lain yang jika dilakukan setiap hari, biayanya juga mahal. Maka dari itu, banyak milenial sekarang yang memilih untuk bekerja di co-working space karena mereka bisa menyewa tempat kerja yang beragam dengan harga yang wajar, serta mendapatkan fasilitas kantor tanpa harus menghabiskan banyak uang.

Cafe dan restoran juga sebenarnya tidak cocok sebagai lingkungan untuk bekerja, mengingat bahwa banyak orang dengan kepentingan yang berbeda berkumpul disana seperti berbincang dengan teman, makan/minum, bekerja, atau bahkan menyaksikan sebuah tontonan yang sedang hangat. Oleh karena itu dibutuhkan sebuah tempat dimana orang dapat bekerja dengan tenang, berkumpul dengan kepentingan yang sama yaitu bekerja. Terutama bagi generasi milenial yang saat ini sedang menyukai tren ruang kerja dengan jenis co-working space. Cafe dan restoran menjadi tujuan untuk tempat bekerja dan tentu menjadi tempat untuk makan dan minum untuk dapat mendukung produktivitas mereka dalam bekerja.

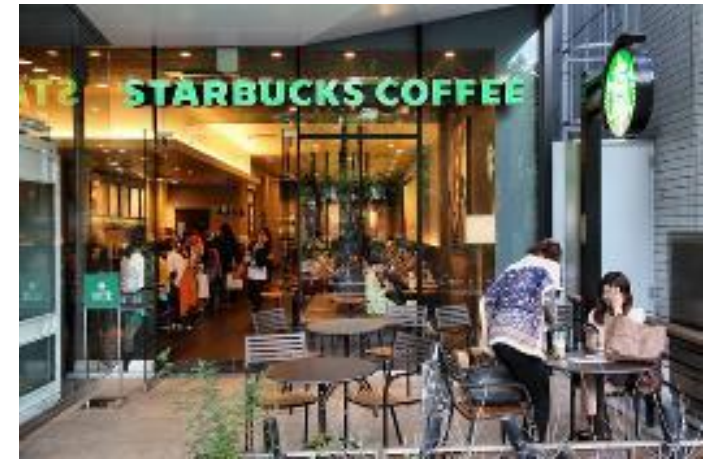

Gambar 1. Starbucks

Sumber: starbucks-re strategimanajemen.ne, 2019

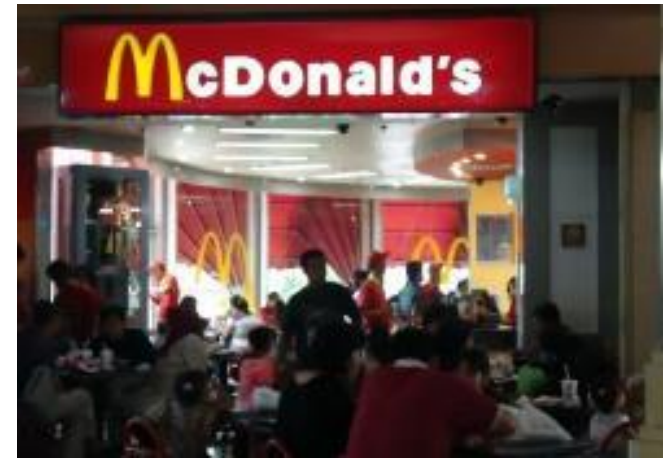

Gambar 2. McDonald

Sumber: id.openrice.com, 2019

Dengan populernya cafe dan restoran sebagai tujuan dari kepentingan yang berbeda membuat tempat-tempat ini menjadi penuh. Dengan adanya suatu program yang dapat menjadi tempat bekerja sekaligus makan dan minum dapat menjadi tujuan alternatif bagi terutama kaum milenial menjadi tempat bekerja dan "nongkrong" bersama teman-teman. Setiap kantor otomotif kebanyakan memiliki gudang dan area servis sendiri pada samping atau belakang. Mereka memakan lahan yang cukup besar untuk ketiga hal tersebut, mengingat bahwa lahan di Jakarta ini sudah sangat terbatas. Oleh karena itu dibutuhkan sebuah cara dimana dapat menggunakan satu lahan seperti dengan cara ditumpuk untuk memenuhi tujuan yaitu efisiensi tanah. Menggabungkan fungsi tempat kerja dan otomotif dalam satu bangunan yang saling terintegrasi satu sama lain.

\section{Pertanyaan Penelitian}

Pertanyaan yang timbul adalah :

a. Tempat kerja jenis seperti apa yang cocok dengan generasi milenial?

b. Mengapa Jakarta Utara (kelurahan Sungai Bambu) terpilih sebagai lokasi tapak terpilih untuk mengadakan proyek Co-Working Space? 
c. Bagaimana caranya untuk dapat menyesuaikan program terpilih dengan tapak yang berdekatan dekat kawasan otomotif dan pergudangan?

d. Bagaimana pendekatan dalam mendesain bentukan bangunan menyesuaikan dengan kriteria pada tapak terpilih?

\section{Batasan Proyek}

Proyek berada di Jakarta Utara, kelurahan Sungai Bambu, kecamatan Tanjung Priok di atas tapak berukuran $7450 \mathrm{~m}^{2}$ dimana menjadi sasaran untuk diadakannya tempat ruang kerja bersama atau Co-Working Space didukung oleh fungsi-fungsi yang disesuaikan dengan kawasan sekitar tapak yaitu, kantor sewa, bengkel, gudang, dan program tambahan food court untuk melayani generasi milenial yang tinggal dekat dengan tapak yang berada ditengah daerah sunter dan kelapa gading yang memiliki banyak pemukiman penduduk. Proyek ini mempunyai besaran tingkat pelayanan kecamatan.

\section{Tujuan Proyek}

a. Menghasilkan sebuah bangunan yang dapat menjadi pilihan utama bagi generasi milenial dalam memilih tempat untuk bekerja terutama pada daerah Jakarta Utara.

b. Memberikan dampak bagi perkembangan ruang kerja bersama (Co-Working Space) serta popularitasnya yang kemudian dapat meningkatkan produktivitas generasi milenial dalam bekerja dan meningkatkan perekonomian.

c. Bertujuan untuk dapat menggantikan destinasi generasi milenial dalam mencari tempat bekerja yang semula adalah cafe dan restoran cepat saji, menjadi tempat kerja khusus yaitu jenis Co-Working Space.

d. Bertujuan untuk mencapai efisiensi tanah dengan menempatkan gudang dibawah tempat kerja, yang sebelumnya memakan tanah yang cukup luas karena kebanyakan bangunan di daerah sekitar tapak adalah kantor otomotif yang dibelakangnya selalu terdapat gudang 1 lantai yang memakan luas cukup besar.

\section{KAJIAN LITERATUR}

\section{Tipe dan Perilaku Arsitektur}

Tipe dan prilaku memiliki hubungan yang sangat kuat dalam arsitektur. Menurut Y.B Mangun Wijaya arsitektur berwawasan perilaku adalah arsitektur yang manusiawi, yang mampu memahami dan mewadahi perilaku-perilaku manusia yang ditangkap dari berbagai macam perilaku, baik itu perilaku pencipta, pemakai, pengamat juga perilaku alam sekitarnya. Dalam bukunya Wastu Citra (1988), pembahasan perilaku ada empat poin yang behubungan dengan arsitektur yaitu :

a. Perilaku manusia didasari oleh pengaruh sosial budaya yang juga mempengaruhi terjadinya proses arsitektur.

b. Perilaku manusia yang dipengaruhi oleh kekuatan religi dari pengaruh nilai-nilai kosmologi.

c. Perilaku alam dan lingkungan mendasari perilaku manusia dalam melakukan arsitektur.

d. Dalam melakukan arsitektur terdapat keinginan untuk menciptakan perilaku yang lebih baik.

Tsukamoto dan Kaijima membagi perilaku ke dalam tiga kategori yaitu manusia, alam, dan bangunan. Perilaku bangunan adalah bentuk respon terhadap perilaku manusia dan alam, serta berbagai perilaku sosial, budaya, dan ekonomi. Oleh sebab itu perilaku sangat berpengaruh terhadap arsitektur yang kemudian menghasilkan tipe-tipe bangunan muncul untuk berperan sebagai pendukung perilaku manusia dan alam.

Perilaku manusia terus berubah seiring dengan perkembangan jaman dan teknologi. Perilaku orang pada jaman dulu dan sekarang tentu berbeda dikarenakan budaya dan kebiasaan yang berubah dari masa ke masa, juga memiliki perbedaan dalam prinsip menggunakan suatu bangunan. Berikut merupakan faktor-faktor yang mempengaruhi dalam prinsip-prinsip perilaku berdasarkan kebutuhan dasar pengguna bangunan menurut (James C Snyder, 1989) antara lain : 


\section{a. Physicological need}

Merupakan kebutuhan dasar manusia yang bersifat fisik. Misalnya makan, minum, berpakaian dan lain-lain yang berhubungan denga factor fisik.

b. Safety need

Kebutuhan akan rasa aman terhadap diri dan lingkungan baik secara fisik maupun psikis, secara fisik seperti rasa aman dari panas, hujan dan secara psikis seperti aman dari rasa malu, aman dari rasa takut dan sebagainya.

\section{c. Affilitation need}

Kebutuhan untuk bersosialisasi, berinteraksi dan berhubungan degan orang lain. Affilitation need sebagai alat atau sarana untuk mengekspresikan diri dengan cara berinteraksi dengan sesamanya.

\section{d. Cognitive/Aestetic need}

Kebuthan untuk berkreasi, berkembang, berfikir dan menambah pengetahuan dalam menentukan keindahan yang dapat membentuk pola prilaku manusia.

\section{Tipe Perilaku Milenial}

Dari berbagai pembagian diatas mengenai tipe dan perilaku arsitektur yang terbagi-bagi berdasarkan usia yang berbeda-beda. Fokus yang mau dicapai untuk kesempatan kali ini adalah kelompok milenial.

Kelompok milenial sendiri dibatasi menurut manusia yang lahir pada tahun 1981-1994. milenial pada umumnya adalah anak-anak dari generasi Baby Boomers dan generasi $X$ yang tua. Generasi X sendiri merupakan manusia yang lahir pada tahun 1965-1980. Dan juga terdapat generasi yang paling baru yaitu generasi $Z$ yang merupakan manusia yang lahir setelah tahun 1995.

Kelompok milenial sekarang ini sedang memasuki usia produktif dan memiliki jumlah terbesar secara global saat ini. Oleh sebab itu harus diperhatikan bagaimana tipe dan perilaku milenial khususnya pada lingkungan perkotaan. Menurut riset Pew Research Center berjudul "Millennials: A Portrait of Generation Next", inilah karakteristik generasi milenial :

a. Milenial lebih percaya User Generated Content (UGC) daripada informasi searah.

b. Milenial wajib punya media sosial.

c. Milenial lebih memilih ponsel dibanding TV.

d. Milenial kurang suka membaca secara konvensional.

e. Milenial lebih tahu teknologi dibanding orangtua mereka.

f. Milenial cenderung tidak loyal namun bekerja efektif.

g. Milenial mulai banyak melakukan transaksi secara cashless.

Karakteristik diatas merupakan keseharian yang turut membentuk perilaku generasi milenial di masyarakat. Hal ini juga mempengaruhi cara kerja. Cara hidup bersosial, preferensi hiburan, selera seni, hingga cara menghabiskan waktu senggang, dll. Sehingga yang kemudian mempengaruhi bagaimana mereka berinteraksi dengan lingkungan tempat hidup mereka dan bagaimana hubungan dengan arsitektur dan seperti apa arsitektur dapat menyesuaikan dengan perilaku yang baru yaitu generasi kaum milenial.

\section{Arsitektur dan Generasi Milenial}

Dengan munculnya perilaku baru di masyarakat menyebabkan pergeseran atau hilangnya tipe arsitektur. Hal ini dapat diambil contoh dari model ruang kerja yang biasanya berbentuk fisik yang kaku sekarang mulai berubah menjadi fleksibel seperti co-working space. Merupakan pendekatan kepada perilaku generasi milenial yang lebih menyukai tempat kerja yang fleksibel. Sebuah model arsitektur harus responsif terhadap lingkungannya, serta sangat representatif terhadap idologi manusia yang menggunakannya. Oleh karena munculnya generasi milenial yang sekarang ini jumlahnya paling mendominasi populasi sehingga arsitektur mulai mengalami pergeseran agar dapat menyesuaikan dengan gaya hidup generasi milenial. 
Contoh lebih lanjut seperti kegemaran generasi milenial untuk traveling dan mengeluarkan dana yang besar. Hal ini kemudian berlanjut kepada ketidakmampuan mereka dalam membeli properti seperti tempat tinggal (rumah) yang disebabkan oleh gaya hidup dan juga mahalnya harga properti saat ini juga menyulitkan generasi milenial dalam memperoleh tempat tinggal sendiri.

Oleh karena itu arsitektur harus dapat menyesuaikan dengan perubahan dan kebutuhan generasi milenial dengan gaya hidup mereka. Mulai dari cara mereka menghabiskan waktu luang, bersenang-senang, tempat tinggal, tempat bekerja, dll. Agar generasi milenial dapat tinggal pada lingkungan hidup mereka dengan nyaman dan produktif.

\section{Generasi Milenial Mempengaruhi Gaya Arsitektur Parkantoran}

Generasi millennial mengubah budaya kantor dengan cara yang nyata. Kita dapat melihat kepekaan mereka akan gaya desain tempat kerja yang modern serta pemikiran akan tata ruang kantor. Mereka juga membuat penyempurnaan figuratif yang secara sekilas akan sedikit lebih sulit untuk dipahami. Berikut ulasan untuk mengetahui bagaimana cara generasi baru ini mengubah konsep tempat kerja, dan bahkan perekonomian di sekitarnya.

a. Menyetarakan hirarki perusahaan dan membuat ruang kantor lebih terbuka

Baik dalam arti harfiah maupun kiasan, generasi milenial ingin menyetarakan jenjang hirarki yang biasa ada pada kebanyakan perusahaan. Tidak perlu lagi ada model kantor dengan bilik-bilik bersekat di lantai bawah dan ruangan besar untuk mereka dengan jabatan tinggi di lantai atas. Hal ini hanya akan menghadirkan hambatan fisik dan psikologis yang dapat mengganggu keharmonisan dan produktivitas kerja karyawan.

Generasi milenial memahami isu ini. Karyawan yang memiliki interaksi langsung dengan manajer mereka dalam enam bulan terakhir terbukti tiga kali lebih terlibat aktif dalam suasana kerja daripada mereka yang tidak berinteraksi dengan pimpinan perusahaan. Kesenjangan interaksi ini adalah sesuatu yang ingin diubah oleh mereka dari generasi milenial selamanya, yaitu dengan mendesain ruang kantor yang terbuka hingga membuka peluang seringnya terjadi proses umpan balik dan bertukar ide.

Generasi milenial mendambakan kesetaraan dalam struktur perusahaan dan jalur komunikasinya. Keterbukaan tidak berarti apa-apa, jika ruang kantor pimpinan tidak mudah untuk diakses. Generasi millenial juga lebih suka bekerja di lingkungan dengan pencahayaan alami, karena hal ini bagi mereka dipercaya mampu menimbulkan rasa keterbukaan dan kebersamaan.

\section{b. Meniadakan konsep 'kantor'}

Ide ini adalah tentang mengizinkan karyawan untuk melakukan pekerjaan mereka di lingkungan yang akrab, nyaman, atau baru. Kita mungkin pernah mendengar tentang ruang kerja komunal, yang menawarkan tempat yang menarik dan lokasinya terletak antara kantor dengan rumah atau kampus. Berkantor di rumah telah menjadi trend berkat generasi millenial. Dalam sebuah survei, $85 \%$ responden milenial menyatakan bahwa mereka lebih suka menggunakan $100 \%$ waktu mereka untuk bekerja dari rumah atau tempat lain, dibandingkan dengan harus pergi ke lokasi kerja.

Ada banyak cara bagi pemberi kerja untuk mendukung konsep ini - bahkan dalam detail yang lebih kecil seperti melengkapi rumah dengan sistem internet atau bahkan satelit. Jika banyak perusahaan mampu memberi karyawan mereka tunjangan untuk membeli perabotan, dekorasi atau benda elektronik untuk tempat kerja mereka di kantor, gagasan tersebut seharusnya juga dapat berlaku untuk mereka yang bekerja dari rumah. Gaji untuk pekerja jarak jauh dapat membantu mereka untuk menciptakan lingkungan kerja yang unik di rumah, sehingga produktivitas mereka dapat meningkat dan membuat mereka merasa lebih terhubung dengan kantor pusat. 


\section{METODE}

Proses dimulai dari penentuan program kegiatan yang lalu diteruskan ke tapak. Program utama co-working space yang kemudian disesuaikan dengan kriteria daerah tapak tersebut. Bangunan didesain berdasarkan kriteria tempat kerja co-working space yaitu keterbukaan. Oleh karena itu bangunan akan didesain kebanyakan menggunakan pencahayaan alami yang dapat menjangkau mayoritas bagian dari bangunan. Untuk dapat melakukan hal tersebut cahaya alami tidak hanya didapat dari bagian tepi terluar bangunan, melainkan juga dari pusat atau center bangunan. Hal tersebut diwujudkan dengan mengadakan ruang terbuka atau pada pusat bangunan juga menggunakan jenis jendela curtain wall yang memaksimalkan cahaya yang masuk kedalam bangunan. Zona co-working space sendiri diletakkan di perbatasan langsung. Desain bangunan disesuaikan dengan gaya arsitektur minimalis, geometris dan elegan serta jendela berukuran tinggi yang menarik banyak perhatian milenials.

Untuk program selain co-working space, program-program lain didapat setelah memilih tapak untuk program co-working space, dengan menggunakan metode pola. Setelah dilihat dari daerah sekitar tapak tersebut kabanyakan adalah kantor otomotif yang sebagian besar bagian belakangnya terdapat gudang yang cukup besar memakan lahan. Oleh karena itu pada proyek diadakan kantor sewa, bengkel dan, area penyimpanan yang cukup besar. Ketiganya saling terintegrasi satu sama lain artinya setiap perusahaan yang menyewa sebuah kantor sewa akan mendapatkan ruang area penyimpanan, yang kemudian bengkel dapat mendapatkan barang dari area penyimpanan yang mendapat koordinasi dari kantor sewa tersebut.

Bentuk bangunan juga didapat menggunakan metode pola, dimana melihat bagaimana pola bangunan sekitar agar tidak menghasilkan bentuk yang dapat mengacaukan kriteria kawasan tersebut. Didapat bahwa bangunan sekitar mempunyai bentuk grid-grid yang memanjang yang sesuai dengan bentuk tapak yang terpilih.

\section{DISKUSI DAN HASIL}

\section{Perkembangan Co-Working Space di Jakarta}

Tempat kerja berjenis Co-Working Space di Indonesia sedang sangat berkembang. Berdasarkan catatan Sekretaris Jenderal Asosiasi Co-working Space Indonesia Felencia Hutabarat sekarang ini tempat kerja Co-Working Space di Indonesia bertambah hingga $400 \%$ dari 45 bangunan pada tahun 2016 dan sekarang sudah mencapai sekitar 200 yang tersebar di seluruh Indonesia. Menurutnya, ada tiga elemen yang membedakan Co-Working Space dengan ruang kantor konvensional, yaitu komunitas (community), kolaborasi (collaboration), dan konektivitas (connectivity).

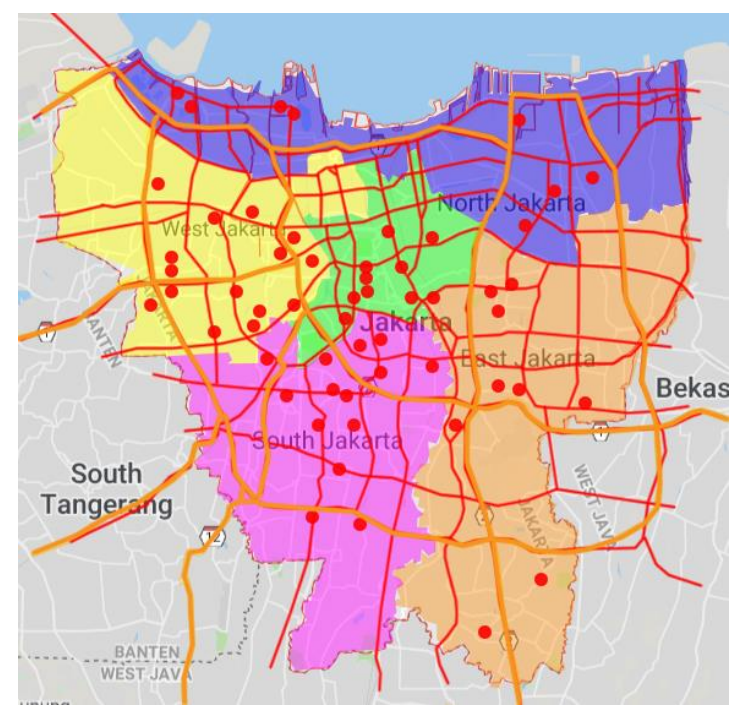

Gambar 3. Pemetaan Co-Working Space di Jakarta Sumber: Penulis, 2019 
Di Jakarta ruang kerja jenis Co-Working Space juga mulai berkembang dilihat dari pemetaan Co-Working Space pada satu area Jakarta. Namun tidak semua dari co-working space tersebut merupakan tempat yang dapat dikunjungi untuk semua orang melainkan kantor yang memiliki gaya co-working space. Dari pemetaan tersebut dapat dilihat bahwa daerah Jakarta Utara masih terdapat sedikit tempat kerja Co-Working Space. Maka diambilah satu area di Jakarta Utara yang masih jarang tempat kerja jenis Co-Working Space yang dekat dengan hunian agar dapat menyediakan tempat kerja bagi mereka yang tidak ingin bekerja dirumah. Area tersebut terdapat diantara daerah Sunter dan Kelapa Gading yang ditandai dengan lingkaran berwarna biru pada pemetaan dibawah

\section{Cafe Sebagai Tempat Kerja Generasi Milenial}

Sekarang ini generasi milenial kebanyakan bekerja atau nongkrong di cafe dan restoran. Oleh karena itu berikut adalah pemetaan cafe Starbucks pada satu Jakarta yang merupakan salah satu tempat yang paling populer untuk menjadi tujuan tempat kerja bagi generasi muda termasuk generasi milenial. Berikut pemetaan Starbucks pada satu Jakarta :

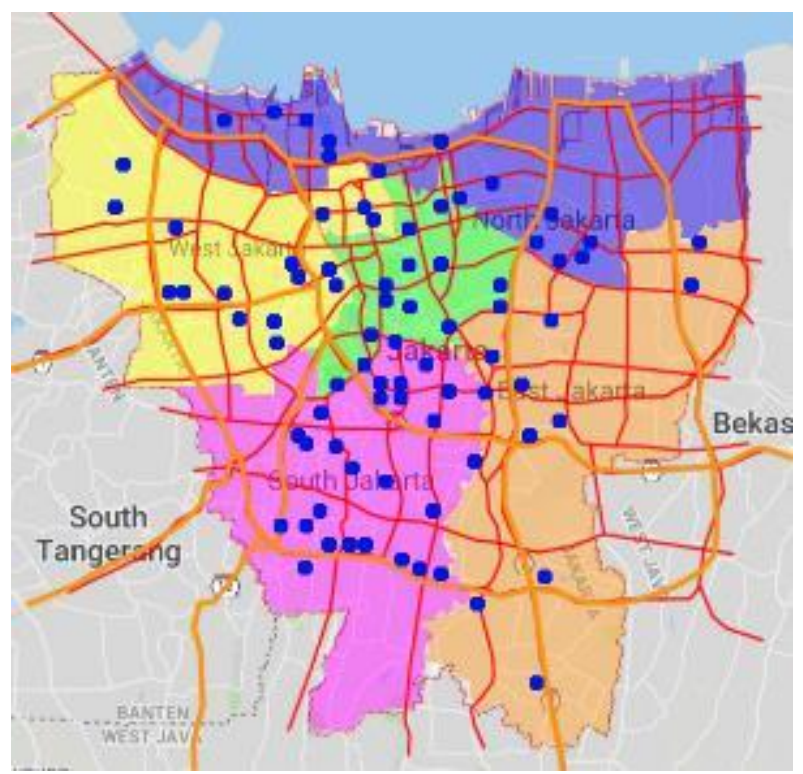

Gambar 4. Pemetaan Starbucks di Jakarta

Sumber: Penulis, 2019

Berdasarkan pemetaan tersebut didapat bahwa jumlah Starbucks yang menjadi tujuan untuk bekerja generasi muda ternyata lebih banyak dibandingkan dengan tempat kerja co-working space pada pemetaan diatas, yang sebenarnya tidak cocok untuk menjadi tempat bekerja mengingat bahwa orang dengan kepentingan yang berbeda berkumpul disana seperti bekerja, makan/minum, mengobrol. Hal tersebut membuatnya menjadi tidak cocok menjadi tempat bekerja karena terkadang dapat memberikan suasana yang bising. Namun karena jumlahnya yang banyak membuatnya menjadi tujuan utama dalam bekerja karena tidak terdapat banyak tempat untuk mendukung kegiatan bekerja seperti co-working space untuk umum. Dengan begitu penyediaan tempat co-working space untuk publik dapat menjadi tujuan utama untuk bekerja terutama untuk daerah Sunter dan Kelapa Gading.

\section{Lokasi}

Setelah menentukan daerah Jakarta Utara dipilihlah daerah yang masih tidak terjangkau tempat kerja jenis co-working space yaitu pada bagian pinggir kecamatan Tanjung Priok. Daerah tersebut juga dipilih karena terdapat banyak hunian yaitu daerah Sunter dan Kelapa Gading. 


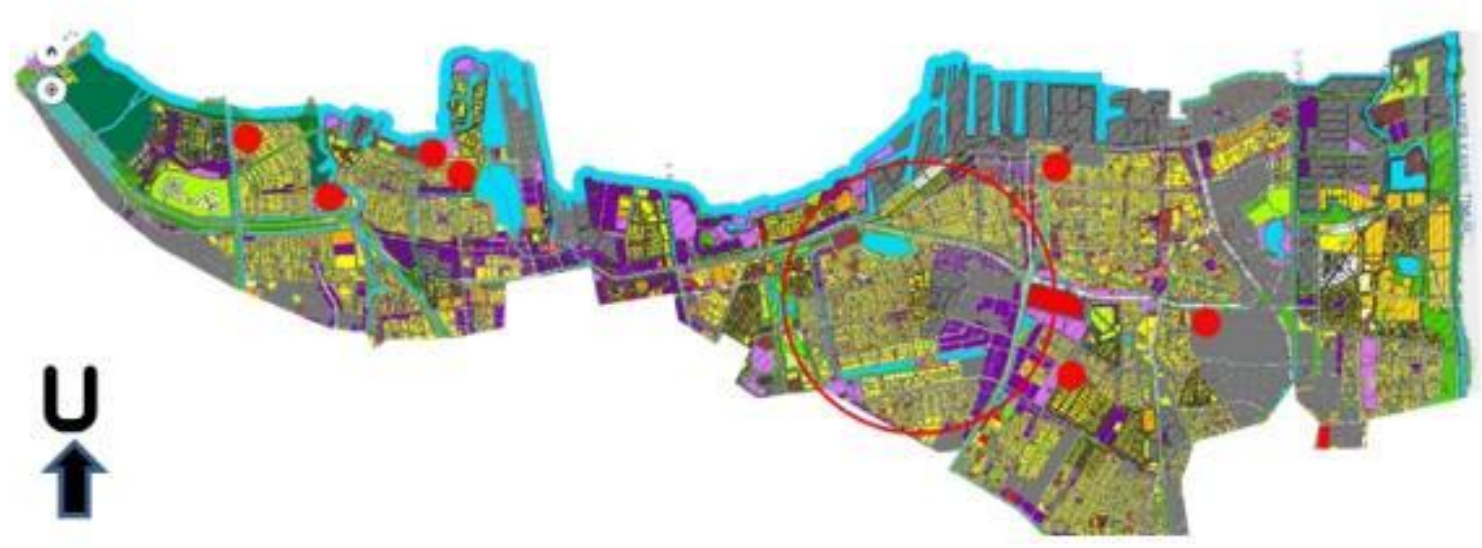

Gambar 5. Peta Zonasi Jakarta Utara

Sumber: https://tataruang.jakarta.go.id, 2019

Setelah menentukan daerah Jakarta Utara dipilihlah daerah yang masih tidak terjangkau tempat kerja jenis co-working space yaitu pada bagian pinggir kecamatan Tanjung Priok. Daerah tersebut juga dipilih karena terdapat banyak hunian yaitu daerah Sunter dan Kelapa Gading.

Sekitar tapak terdapat perkantoran mobil dan banyak pergudangan. Dengan daerah tapak yang seperti itu jenis program co-working space yang ada pada tapak terpiih tersebut adalah ruang-ruang kantor sewa yang didampingi dengan fasilitas ruang penyimpanan bagi yang menyewa ruang kerja pada bangunan ini. Area komunal atau co-working space untuk yang melayani secara umum juga disediakan agar bangunan ini tidak terbatas pada perusahaan, tapi juga untuk generasi milenial perorangan yang ingin mencari tempat kerja selain di rumah dan cafe. Oleh karena dapat mendukung dengan banyaknya hunian disekitar tapak.

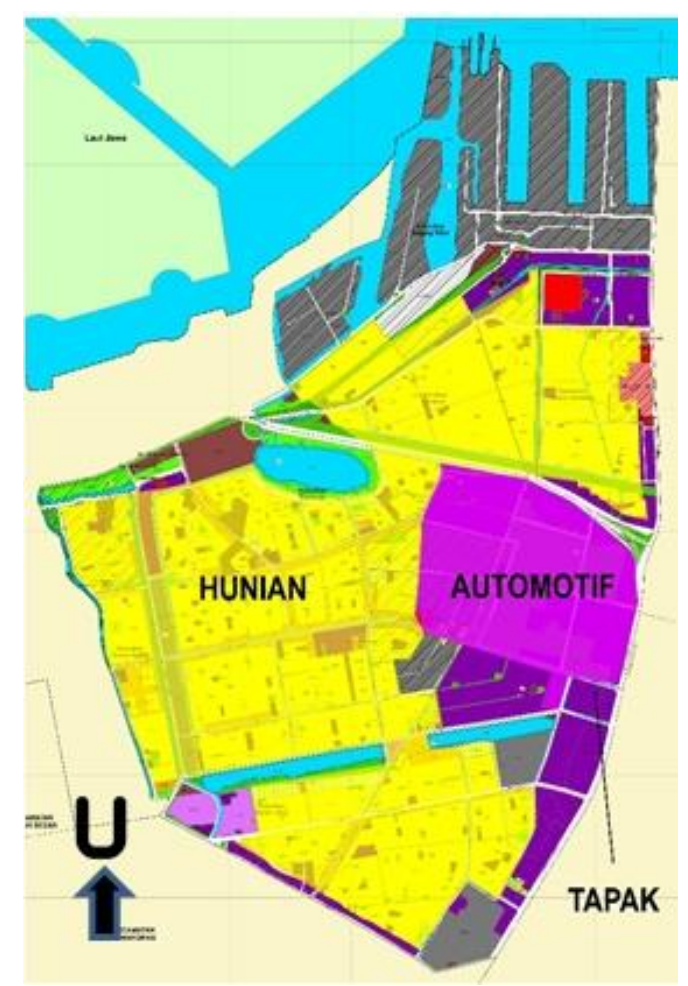

Gambar 6. Peta Zonasi Kecamatan Tanjung Priok Sumber: Penulis, 2019 


\section{Zona Hunian}

Tapak berada di perbatasan antara sunter dan kelapa gading. Program melayani generasi milenial yang mencari tempat untuk bekerja dengan jenis co-working space dan dapat menjadi tempat "nongkrong" bagi mereka yang hanya ingin makan dengan pilihan makanan yang bervariasi tanpa harus ke mall dengan program food court yang disediakan. Generasi milenial yang ditargetkan adalah daerah sunter dan kelapa gading dengan banyaknya hunian pada daerah sekitar tapak. Letak tapak yang dekat dengan hunian-hunian tersebut juga dapat mengurangi kepadatan kendaraan sampai keluar kawasan.

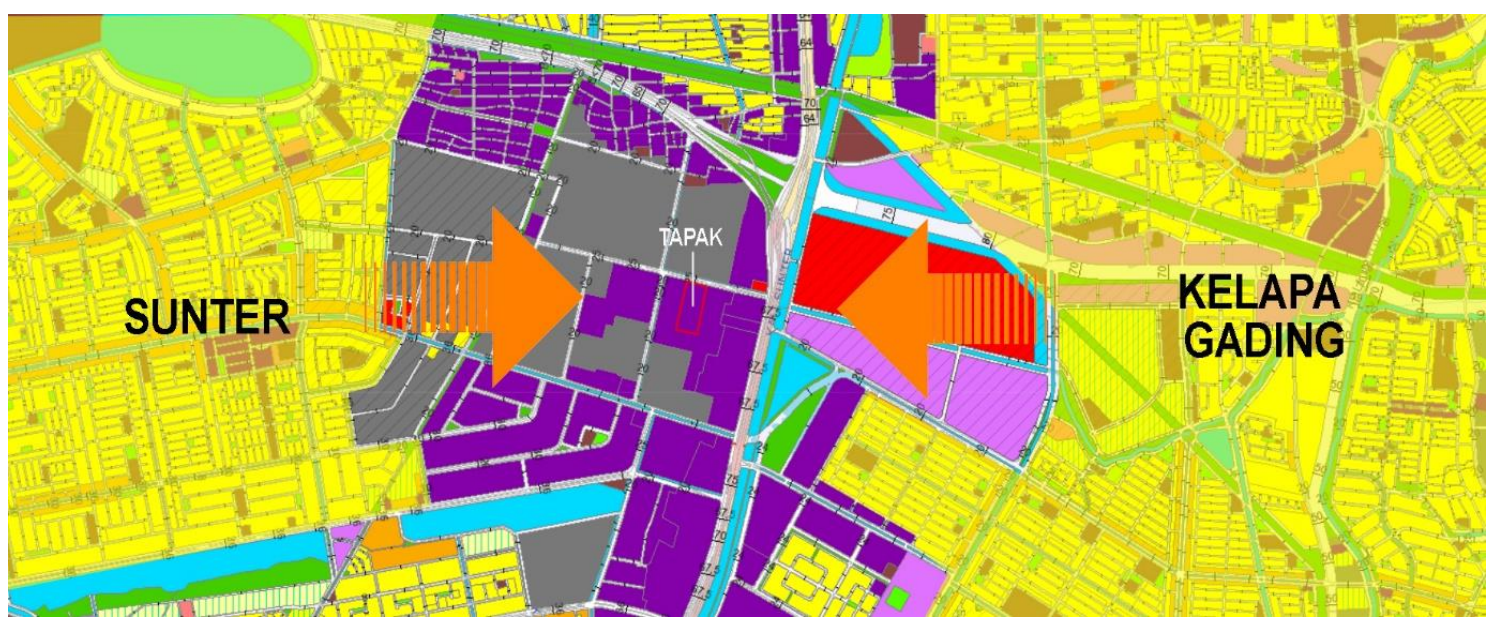

Gambar 7. Analisis Kecamatan Tanjung Priok Sumber: Penulis, 2019

\section{Zona Perkantoran dan Pergudangan}

Pada bagian seberang tapak terdapat satu kawasan automotif yang terdapat seperti showroom mobil, bengkel (servis), kantor perusahaan automotif. Pada kawasan automotif tersebut juga terdapat fasilitas pendukung mereka seperti gudang-gudang. Gudang-gudang yang berada disekitar tapak tersebut tidak semuanya diitujukan untuk automotif melainkan beragam. Kedua fasilitas tersebut dimasukan kedalam program yaitu dengan adanya ruang penyimpanan, bengkel untuk mobil dan motor serta kantor sewa yang semuanya saling terintegrasi satu sama lain.

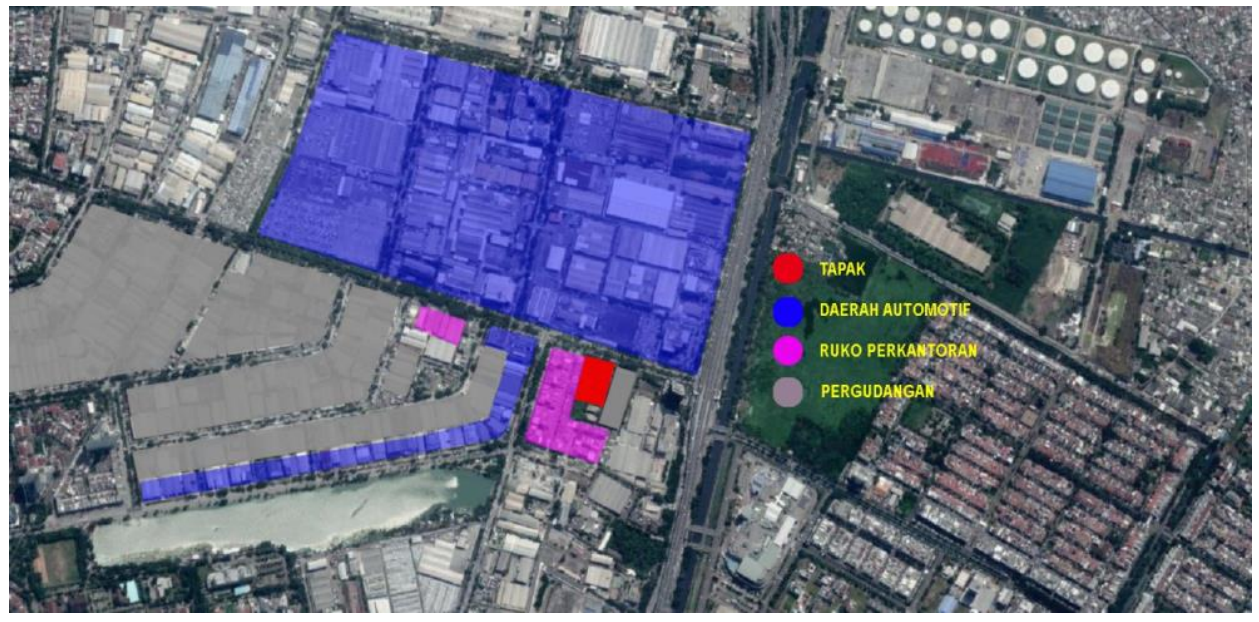

Gambar 8. Daerah Automotif dan Pergudangan Dekat Tapak

Sumber: Penulis, 2019 


\section{Analisa Tapak}

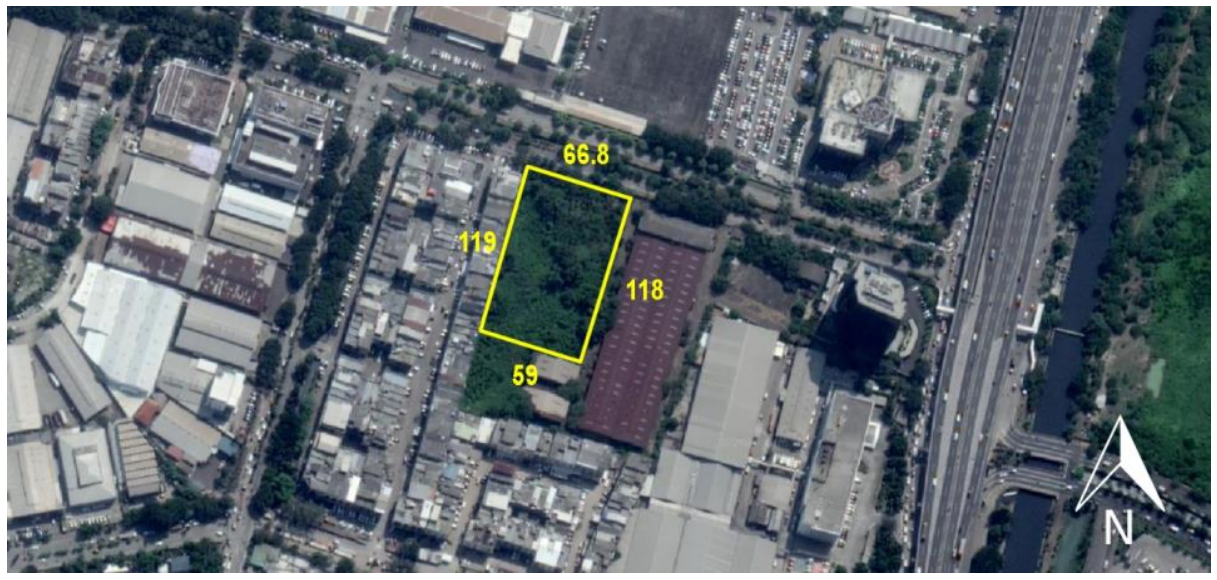

Gambar 9. Ukuran Tapak

Sumber: Penulis, 2019

$\begin{array}{lll}\text { Kecamatan } & : & \text { Tanjung Priok } \\ \text { Kelurahan } & : & \text { Sungai Bambu } \\ \text { Sub Zona } & : & \text { K.1 } \\ \text { Zona } & : & \text { Zona Perkantoran, }\end{array}$

Perdagangan, Dan Jasa

$\begin{array}{lll}\text { KDB } & : & 50 \\ \text { KLB } & : & 2 \\ \text { KB } & : & 4 \\ \text { KDH } & : & 30 \\ \text { KTB } & : & 55 \\ \text { Luas tapak } & : & 7450 \mathrm{~m}^{2}\end{array}$

Gambar 10. Peta Zonasi Sekitar Tapak Sumber: https://tataruang.jakarta.go.id, 2019

\section{Akses Busway}

Tapak berada sangat dekat dengan halte busway yang berjarak $100 \mathrm{~m}$, sehingga masih ideal untuk ditempuh dengan berjalan kaki berdasarkan Peraturan Menteri Pekerjaan Umum No 03/PRT/M/2014 dengan jarak maksimal 400m. Halte busway berada di perbatasan antara sunter dan kawasan kelapa gading.

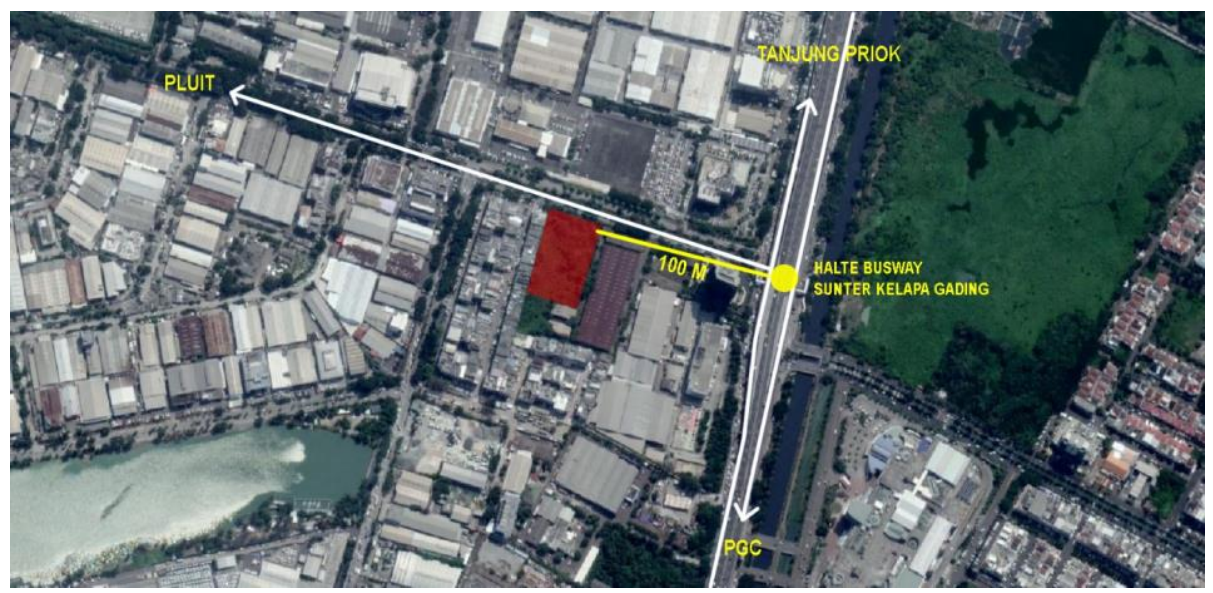

Gambar 11. Jalur dan Akses Busway Sumber: Penulis, 2019 


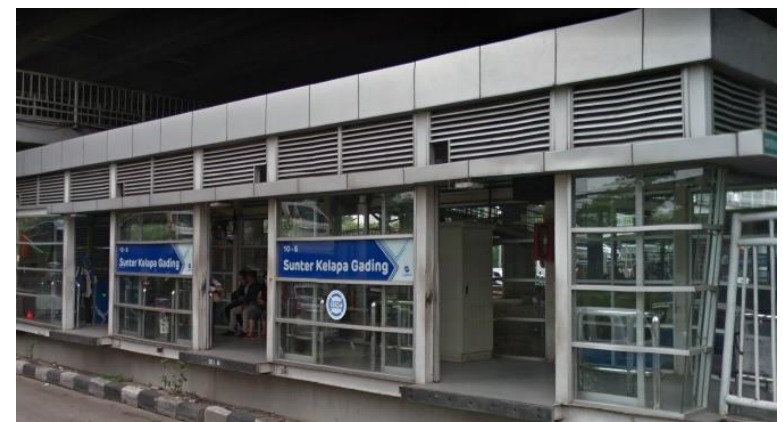

Gambar 12. Halte Busway Sunter Kelapa Gading Sumber: Penulis, 2019

\section{Hirarki Jalan}

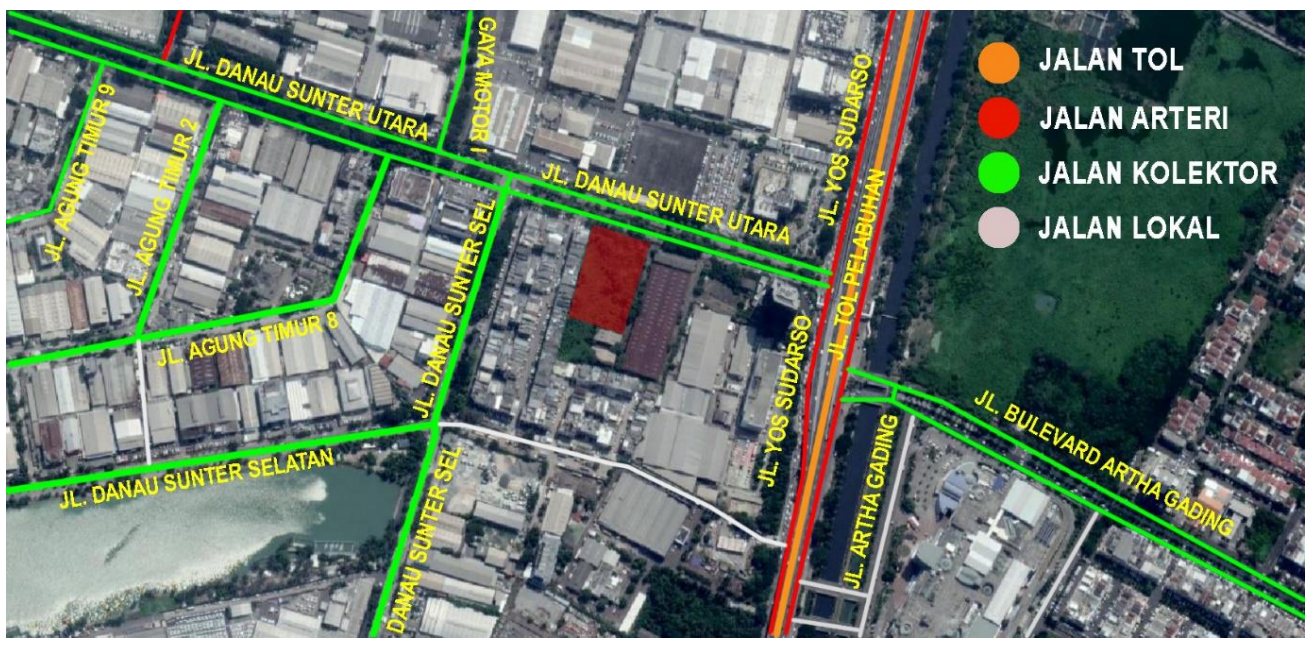

Gambar 13. Hirarki Jalan

Sumber: Penulis, 2019

Jalan depan tapak merupakan jalan kolektor Danau Sunter Utara yang terdiri dari dua lajur jalan. Jalan tersebut merupakan satu-satunya jalan untuk mengakses tapak ini. Jalan Danau Sunter Utara terhubung dengan Jalan Yos Sudarso yang merupakan jalan arteri. Tapak juga berada dekat dengan Jalan Tol Pelabuhan. Dan berjarak $1.2 \mathrm{~km}$ dari pintu keluar tol Sunter/Podomoro Kelapa Gading.

Jalan sekitar tapak mempunyai jenis konfigurasi jalur yang linear. Konfigurasi jalan yang linear menurut Ching (2008) adalah seluruh jalan mempunyai bentuk linear. Namun jalur yang lurus dapat menjadi elemen pengatur yang utama bagi serangkaian ruang, sebagai tambahan, jalur ini dapat berbentuk kurvalinear atau terpotong-potong, bersimpangan dengan jalur lain, bercabang, atau membentuk sebuah putaran balik.

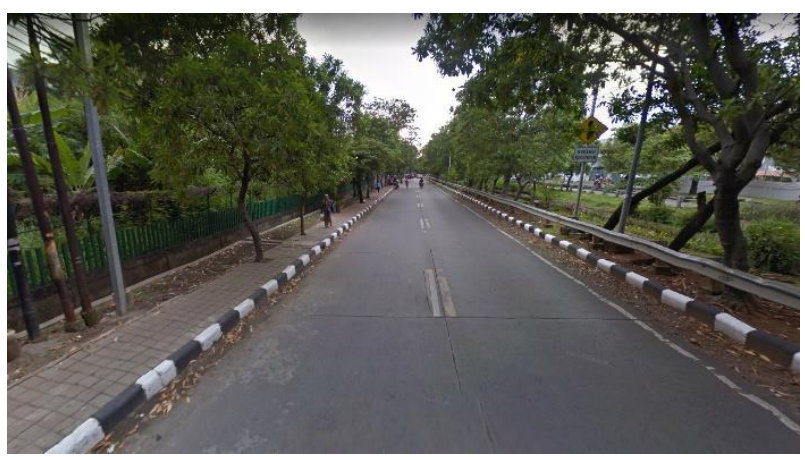

Gambar 14. Jl Danau Sunter Utara

Sumber: Penulis, 2019 


\section{Entrance}

Akses masuk menuju tapak hanya ada satu yaitu melalui Jalan Danau Sunter Utara. Pintu masuk tersebut ideal untuk tapak tersebut.

Menurut Francis D.K.Ching seperti apapun bentuk ruang yang dimasuki, atau apapun bentuk penutupnya, penanda pintu masuk ke dalam ruang tersebut, paling baik adalah berupa sebuah bidang, langsung atau tidak langsung, yang mengarah tegak lurus terhadap jalur pencapaiannya.

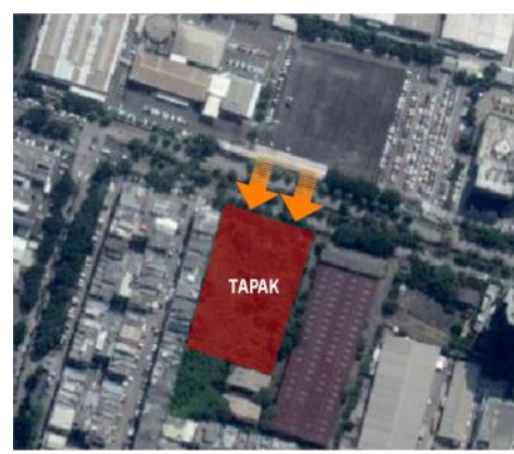

Gambar 15. Entrance Tapak Sumber: Penulis, 2019
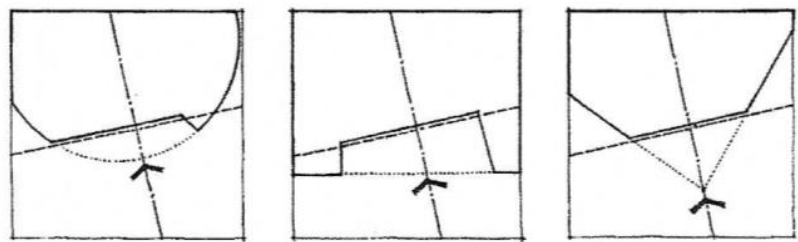

Gambar 16. Pintu Masuk Ideal

Sumber: Ching, 2008

\section{Sirkulasi}

Sirkulasi kendaraan pada jalan sekitar tapak dan akses pejalan kaki melalui jalur pedestrian pada depan tapak, tepi Jl. Danau Sunter Utara.

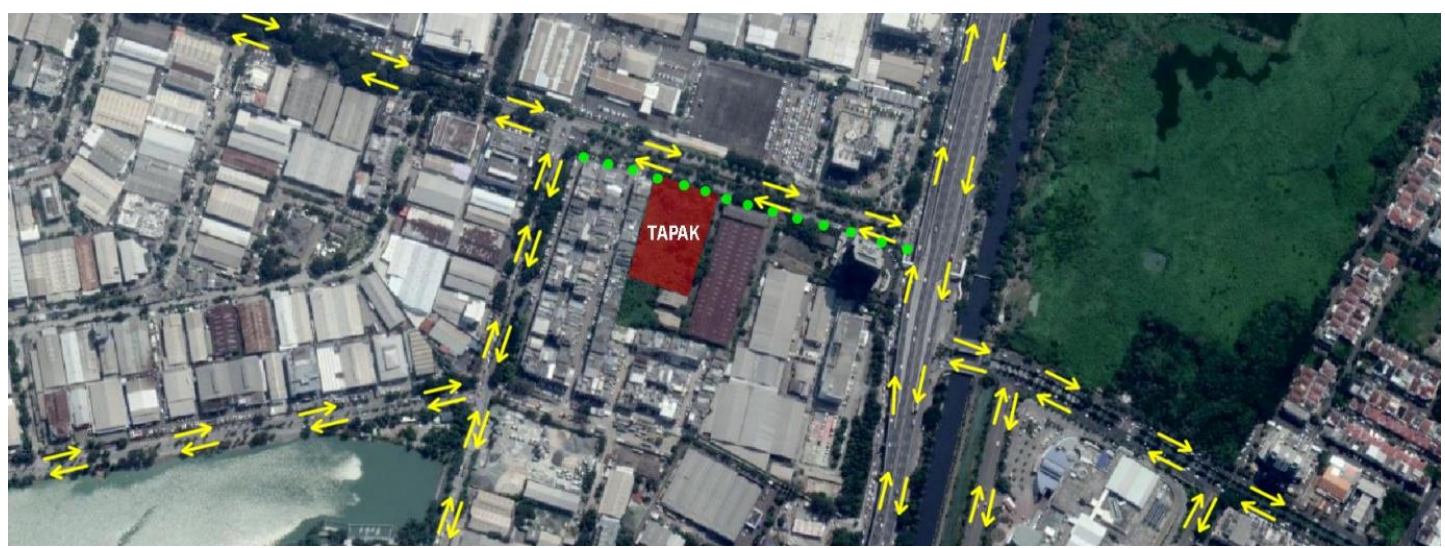

Gambar 17. Sirkulasi Kendaraan dan Akses Pejalan Kaki

Sumber: Penulis, 2019

\section{Akses Jalan Tol}

Jarak dari tapak ke pintu masuk tol podomoro adalah $2.3 \mathrm{~km}$ dan jarak pintu keluar tol sunter/kelapa gading ke tapak adalah $2 \mathrm{~km}$. 


\section{Hasil Perancangan}

Perspektif Eksterior

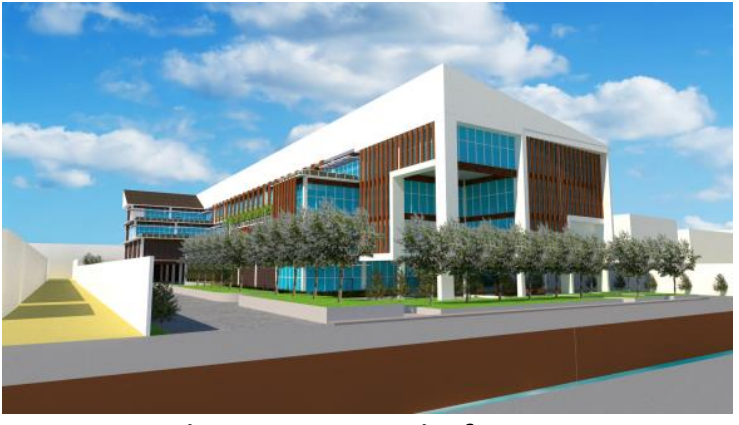

Gambar 18. Perspektif Human View Sumber: Penulis, 2019

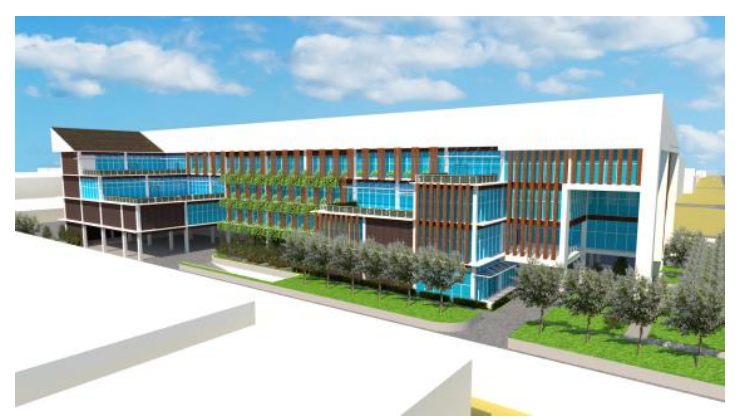

Gambar 20. Perspektif Bird View Sumber: Penulis, 2019

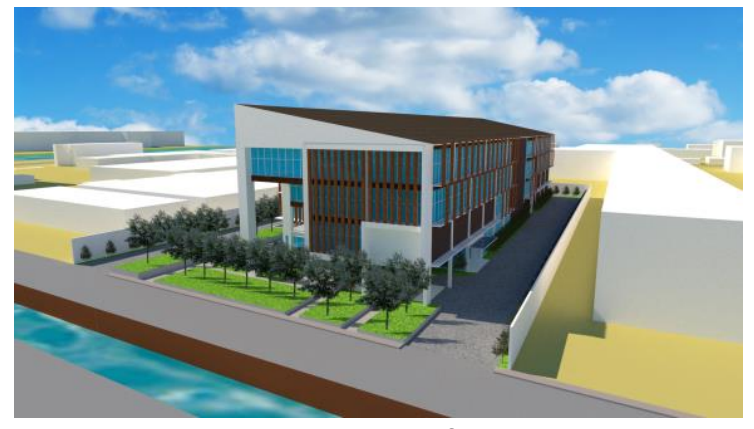

Gambar 19. Perspektif Samping Kanan Sumber: Penulis, 2019

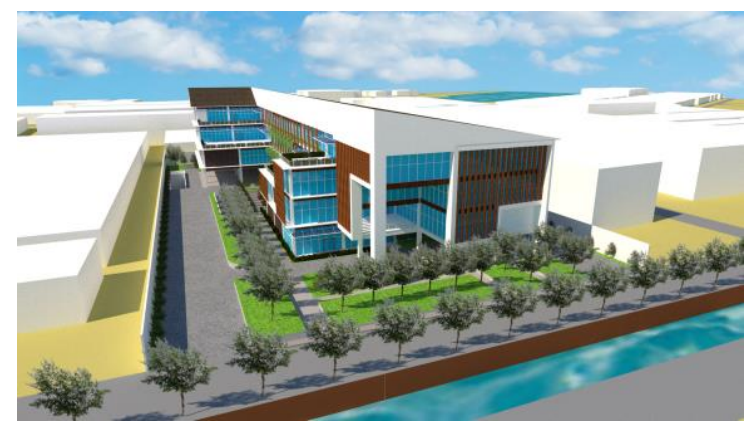

Gambar 21. Perspektif Samping Kiri Sumber: Penulis, 2019

\section{Exploded Denah}

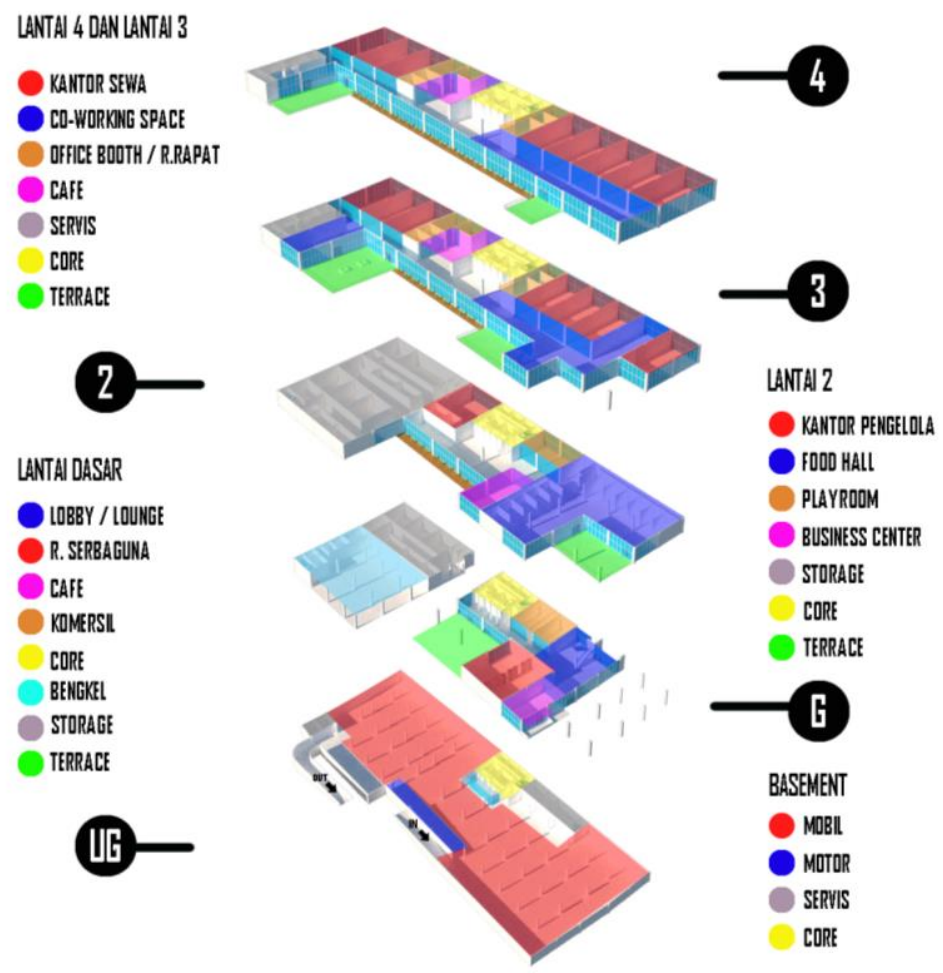

Gambar 22. Exploded Denah Sumber: Penulis, 2019 


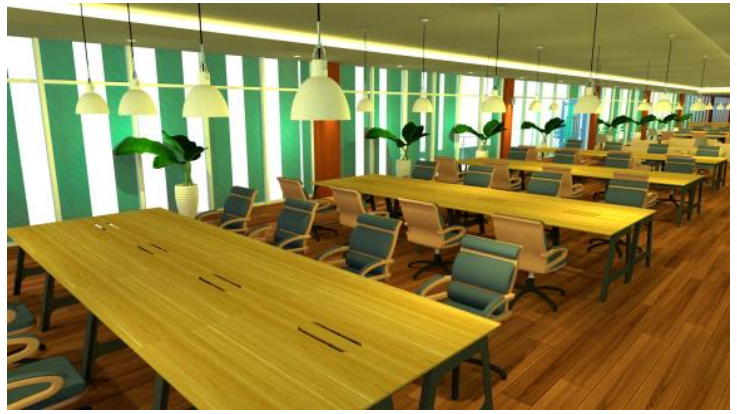

Gambar 23. Co-Working Space Sumber: Penulis, 2019

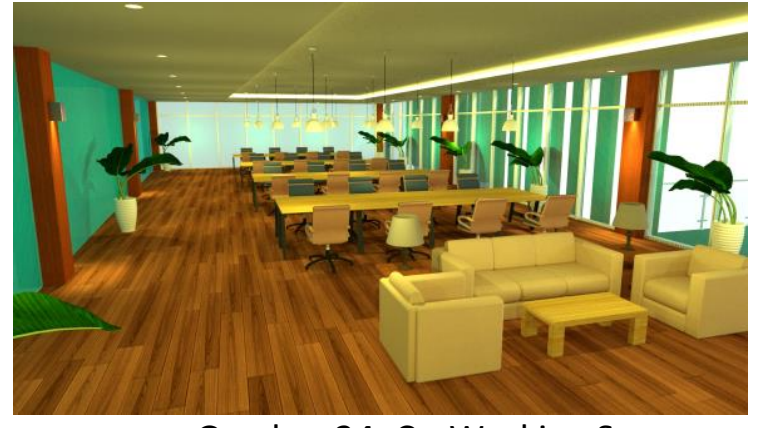

Gambar 24. Co-Working Space Sumber: Penulis, 2019

\section{KESIMPULAN}

Sekarang ini cafe menjadi pilihan utama anak-anak muda termasuk generasi milenial dalam bekerja. Hal tersebut sebenarnya tidak cocok karena orang-orang dengan berbagai kepentingan datang kesana, sehinga terkadang menimbulkan kebisingan Oleh karena itu kita harus mengembangkan dan memeratakan jenis tempat kerja co-working space yang sekarang ini belum tersebar secara merata di Jakarta. Jenis tempat kerja co-working space juga menjadi tempat favorit anak muda sekarang dalam bekerja karena dinilai lebih santai dan dapat bertemu dengan orang atau bersosialisasi, bahkan membangun relasi kerja.

Rencana program co-working space akan ditempatkan pada daerah Jakarta Utara karena daerah tersebut merupakan daerah yang paling sedikit terdapat co-working space. Program co-working space terpilih sebagai program utama juga disesuaikan dengan program yang sesuai dengan daerah sekitar tapak yaitu kantor-kantor otomotif dan gudang, oleh karena itu disediakan juga program seperti kantor sewa, bengkel, dan ruang penyimpanan yang cukup besar yang terintegrasi dengan bengkel dan ruang kantor tersebut. Program-program pendukung juga disediakan seperti food hall dan book lounge.

Desain bangunan akan menyesuaikan dengan gaya arsitektur generasi milenial yaitu arsitektur minimalis, geometris dan elegan serta jendela berukuran tinggi seperti curtain wall yang sekarang ini banyak menarik perhatian milenials. Juga memperhatikan bentukan bangunan sekitar tapak yang berbentuk grid memanjang untuk disesuaikan dengan desain massa bangunan.

\section{REFERENSI}

Bunga, R. (2018). Bukan Sekadar Tempat Kerja, 'Co-working Space' Jadi Tren Baru Milenial. Diambil kembali dari IDN Times: https://www.idntimes.com/life/career/rully-bunga/bukansekadar-tempat-kerja-coworking-space-jadi-tren-baru-millennial-1/full

Ching, F. D.K. (2008). Arsitektur : Bentuk, Ruang, dan Tatanan. Jakarta: Erlangga

Elliot, F. (2017). Take a Look Around Downtown's Highly Anticipated Corporation Food Hall. Diambil kembali dari Eater Los Angeles: https://la.eater.com/2017/9/5/16256808/corporation-food-hall-downtown-photos-inside

Haries. (2018). Kaum Milenial dan Fenomena Geliat Properti di Indonesia. Diambil kembali dari Arsdesain: https://arsdesain.com/kaum-milenial/

Luciana, A. (2018). Prospek Cerah, Jumlah Coworking Space Indonesia Naik 400 Persen. Diambil kembali dari Tempo: https://bisnis.tempo.co/read/1101327/prospek-cerah-jumlahcoworking-space-indonesia-naik-400-persen

Nuring, A. (2018). Diambil kembali dari Arginuring Arsitek: https://www.arginuring.com/blog/tag/trend-d esain-millenia/ 
Nuring, . (2018). 5 Cara Generasi Millennial Mengubah Budaya Kerja Dan Desain Kantor. Diambil kembali dari Arginuring Arsitek: https://www.arginuring.com/blog/2018/07/11/5-caragenerasi-millennial-mengubah-budaya-kerja-dan-desain-kantor/

Sari, I. K. (2017). Generasi Milenial Turut Pengaruhi Gaya Arsitektur Indonesia. Diambil kembali dari Kumparan: https://kumparan.com/@kumparanstyle/generasi-milenial-turutpengaruhi-gaya-arsitektur-indonesia

Todd, C. (2018). 10 Ways Coworking Offices Can Save Businesses Money. Diambli kembali dari Coworker : https://www.coworker.com/lab/10-ways-coworking-offices-can-savebusinesses-money/

Tjahjono, G. (2000). Metode Rerancangan Suatu Pengantar untuk Arsitek dan Perancang. Jakarta: Universitas Indonesia

Weber. (2018). Millennials: Membentuk Gaya Arsitektur Masa Depan?. Diambil kembali dari Weber id: https://www.id.weber/en/node/516

Whiteboard Jurnal. (2018). Melihat Kultur Kerja Baru Millennial. Diambil kembali dari Whiteboard Jurnal: https://www.whiteboardjournal.com/ideas/human-interest/melihat-kultur-kerjabaru-milennial/

White, E. T. (1985). Analisa Tapak. Bandung: Intermata 
